\title{
A comparative study between total laparoscopic hysterectomy and total abdominal hysterectomy for benign uterine pathologies at tertiary care institute, Udaipur
}

\author{
Shatendra Kumar Goyal*, Madhubala Chauhan, Babita Kanwat, Dinesh Mehra
}

Department of Obstetrics and Gynaecology, RNT Medical College, Udaipur, Rajasthan, India

Received: 26 July 2021

Accepted: 27 September 2021

\section{*Correspondence:}

Dr. Shatendra Kumar Goyal,

E-mail: sbapna.1@gmail.com

Copyright: (c) the author(s), publisher and licensee Medip Academy. This is an open-access article distributed under the terms of the Creative Commons Attribution Non-Commercial License, which permits unrestricted non-commercial use, distribution, and reproduction in any medium, provided the original work is properly cited.

\section{ABSTRACT}

Background: Hysterectomy is one of the most commonly performed procedures in gynaecological surgery. The most common indication is benign uterine disease. As the time is passing trend is towards those approaches which are minimally invasive, less painful, have less complications, less blood loss and are more cosmetic. Thus, total laparoscopic hysterectomy has gained popularity. The purpose of this study was to compare the 2 different routes of hysterectomy.

Methods: In this prospective randomized observational study patients undergoing both the types of hysterectomy, that is, TAH (total abdominal hysterectomy) and TLH (total laparoscopic hysterectomy) during 2 year period at Rajkiya Pannadhay Mahila Chikitsalaya RNT medical college Udaipur were included in the study. 50 women (25 in each group) aged between 31-72 years were included into the study.

Results: We observed that duration of surgery was found to be longer in TLH than TAH $(112.56 \pm 19.45$ min versus $57.9 \pm 19.26 \mathrm{~min}, \mathrm{P}<0.001(\mathrm{HS}))$. The length of hospital stay was less in TLH than TLH $(\mathrm{p}=0.0001)$ and the amount of intra-operative blood loss were also less in TLH than TAH $(163.60 \pm 44.15$ versus $313.20 \pm 123.48 \mathrm{ml}, \mathrm{p}<0.001)$. TLH group had early ambulation compared to TAH group $(2.24 \pm 0.44$ day versus $3.12 \pm 0.33$ day, $\mathrm{p}<0.001)$, difference on the basis of length of hospital stay was highly significant which was shorter in TLH than TAH (4.40 \pm 1.15 versus $10.32 \pm 8.19$ days, respectively; $\mathrm{p}<0.001)$. In current study patient satisfaction level was found highly significant between TLH and TAH $(100 \%$ versus $56 \%, \mathrm{p}<0.001)$.

Conclusions: TLH is a safe and effective method of doing hysterectomy. The present study concluded that TLH is associated with less hospital stay, less blood loss, less use of analgesics, early ambulation, early start of oral feed, and better patient satisfaction.

Keywords: TLH, TAH, Hysterectomy, Benign uterine pathology

\section{INTRODUCTION}

Term hysterectomy though means removal of uterus, in practice it has a much wider classification depending upon the indication. At times it is done without removal of the cervix (supracervical hysterectomy) or with removal of adnexa (hysterectomy with salpingo-oophorectomy). It can also be a part of staging laparotomy or radical hysterectomy. Hysterectomy can be performed abdominally, vaginally or through abdominal ports with help of a laparoscope. ${ }^{2}$

Factors that influence the route of hysterectomy includes indication for surgery, size of the uterus, presence or absence of associated pelvic pathology, surgeon's training, preference and patient's choice. ${ }^{3}$ 
Laparoscopic hysterectomy was reported to have lower postoperative morbidity, improved quality of life, less hospital stays, less blood loss, minimal pain, faster wound healing, recovery and cosmetically looks better when compared to laparotomy. ${ }^{4,5}$

With regard to hysterectomies performed for benign disease, the number of abdominal hysterectomies is decreasing but laparoscopic and robotic assisted laparoscopic procedure are on the increase. ${ }^{6}$

Conservative medical management of some disease like fibroid uterus after the introduction of ulipristal acetate/mifepristone have reduced the number of hysterectomies.

TLH will maintain the length of vagina, vault support as well as the integrity of pelvic floor. The rate of complications can be reduced by introduction of a simple and safe method. So, TLH may supersede all other techniques presently used.

Benign diseases are the most common indication in which more than $70 \%$ of them result in hysterectomies. These include menstrual disorders, fibroids, pelvic pain. ${ }^{7}$

Though the abdominal hysterectomy was an accepted approach, it was associated with substantial morbidity and wound problems to incisional hernias in the long run. ${ }^{8}$

Laparoscopic approach has been found to be a better alternative as it has the advantage over laparotomy, that is, possibility of thorough abdominal inspection to assess the abdominal cavity for extra-uterine spread and collection of peritoneal fluid for cytology. Moreover, the abdominal wound in this case is very small thereby resulting in lesser complications, shorter hospital stays and faster return to the daily life. ${ }^{9}$

The first laparoscopic hysterectomy was performed and published in 1989 by Harry Reich for endometriosis, but it was only from 1991 onwards that this surgical method became common in use. ${ }^{8,10}$

The advantage of laparoscopic approach seems to be more pronounced in obese and younger patients. ${ }^{11}$

Although laparoscopic surgeries were widely performed in private setups, very few government hospitals and institutions have been successful in establishing this advanced mode of surgery in their day-to-day practice. Problem of maintenance of costly equipment, excess patient load, limited time and fear of complications are the main constraints in the minds of surgeons, preventing them from undertaking this initiative.

\section{Aims and objectives}

The aims and objectives of the study were to compare the 2 different approaches of hysterectomy, TLH and TAH and to find out the most efficient route of hysterectomy in women with mobile non-prolapsed uteri up to 12 weeks size by comparing the intra and post-operative results.

\section{METHODS}

This was a hospital based prospective randomized observational study conducted in the Department of Obstetrics and gynaecology, RNT medical college, Udaipur, Rajasthan during the period of January 2019 to December 2020.

Total 50 patients were recruited in the study of which 25 patients were included in TLH group and 25 in TAH group after taking approval from the ethics board of Rajasthan university of health sciences. Screening of patients were done for surgery and those patients requiring hysterectomies for benign uterine conditions were posted for either TAH or TLH.

Intra-operative complications were categorized as injury to bladder/ureter/bowel/vessel or none. Patients in postoperative period were monitored for fever, paralytic ileus, nausea and vomiting, urinary tract infections, secondary hemorrhage. Follow up of patients was done upto 4 weeks.

\section{Inclusion criteria}

Patients with benign uterine conditions diagnosed by (Pap smear, biopsy and USG) admitted for hysterectomy and with uterine size $\leq 12$ weeks were included in the study.

\section{Exclusion criteria}

Patient unfit after pre-anaesthetic examination, complex and fixed adnexal mass, malignancies, size of uterus $>12$ weeks and/or size of adenexal mass $>8 \mathrm{~cm}$ were excluded from the study.

Detailed history including presenting complaints, menstrual history, obstetrical history, personal history, past and family history, medical, surgical history were taken.

Complete general and pelvic examination was done. Pap smear, endometrial sampling and whole abdomen ultrasound investigation were done to rule out malignancy.

\section{Statistical analysis}

The data thus collected was analyzed using both descriptive and inferential statistics. The mean and standard deviation were computed. The data on sample characteristics were described in form of tables and graphs. Inferential statistics were used according to the data. The Microsoft excel SPSS version 16.0 software was used for analysis of the data. 


\section{RESULTS}

Wound gaping (24\%) was the highest postoperative complications seen in TAH group.
In TLH group catheter was removed on 2 nd day postoperative in all the cases as in cases of TAH it prolonged upto 21 days in few cases.

Table 1: Distribution of groups according to postoperative complication.

\begin{tabular}{|llllllll|}
\hline \multirow{2}{*}{ Postoperative complications } & \multicolumn{2}{l}{ TAH $(\mathbf{n}=\mathbf{2 5})$} & \multicolumn{2}{l|}{ TLH $(\mathbf{n}=\mathbf{2 5})$} & \multicolumn{2}{l|}{ Total } & P value \\
\cline { 2 - 9 } Fever & No. & $\%$ & No. & $\%$ & No. & $\%$ & 0.31 \\
\hline Wound gaping & 1 & 4 & 0 & 0 & 1 & 2 & 0.009 \\
\hline Nil & 6 & 24 & 0 & 0 & 6 & 12 & 0.004 \\
\hline Total & 18 & 72 & 25 & 100 & 43 & 86 & \\
\hline
\end{tabular}

Table 2: Distribution of groups on the basis of total duration of hospital stay.

\begin{tabular}{|llllllll|}
\hline $\begin{array}{l}\text { Total duration of hospital } \\
\text { stay (days) }\end{array}$ & \multicolumn{2}{l}{ TAH $(\mathbf{n = 2 5})$} & \multicolumn{2}{l|}{ TLH $(\mathbf{n = 2 5})$} & Total & P value \\
\hline $\mathbf{3 - 5}$ & No. & $\%$ & No. & $\%$ & No. & $\%$ & \\
\hline $\mathbf{6 - 1 0}$ & 0 & 0 & 25 & 100 & 25 & 50 & $<0.001$ \\
\hline $\mathbf{2 1 - 2 5}$ & 21 & 84 & 0 & 0 & 21 & 42 & $<0.001$ \\
\hline $\mathbf{3 1 - 3 5}$ & 2 & 8 & 0 & 0 & 2 & 4 & 0.15 \\
\hline Total & 2 & 8 & 0 & 0 & 2 & 4 & 0.15 \\
\hline Mean \pm SD & 25 & 100 & 25 & 100 & 50 & 100 & \\
\hline
\end{tabular}

Table 3: Distribution of groups according to oopherectomy.

\begin{tabular}{|c|c|c|c|c|c|c|c|}
\hline \multirow{2}{*}{ Oopherectomy } & \multicolumn{2}{|c|}{ TAH $(n=25)$} & \multicolumn{2}{|c|}{ TLH $(n=25)$} & \multicolumn{2}{|c|}{ Total } & \multirow{2}{*}{ P value } \\
\hline & No. & $\%$ & No. & $\%$ & No. & $\%$ & \\
\hline Done & 24 & 96 & 15 & 60 & 39 & 78 & \multirow{2}{*}{0.002} \\
\hline Not done & 1 & 4 & 10 & 40 & 11 & 22 & \\
\hline Total & 25 & 100 & 25 & 100 & 50 & 100 & \\
\hline
\end{tabular}

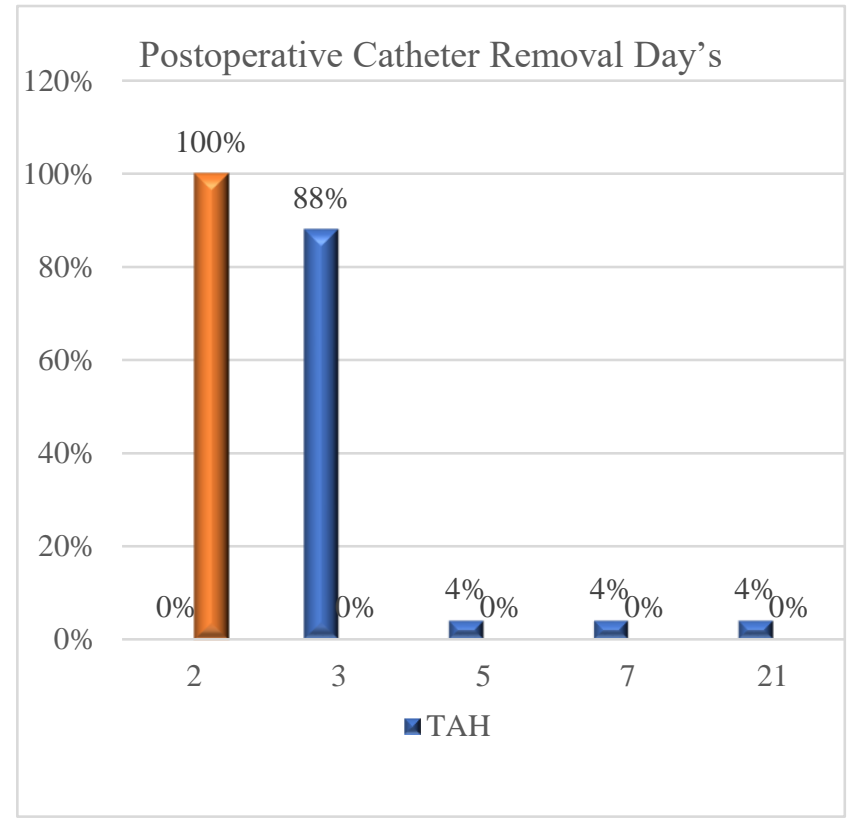

Figure 1: Distribution of groups on the basis of postoperative catheter removal days.

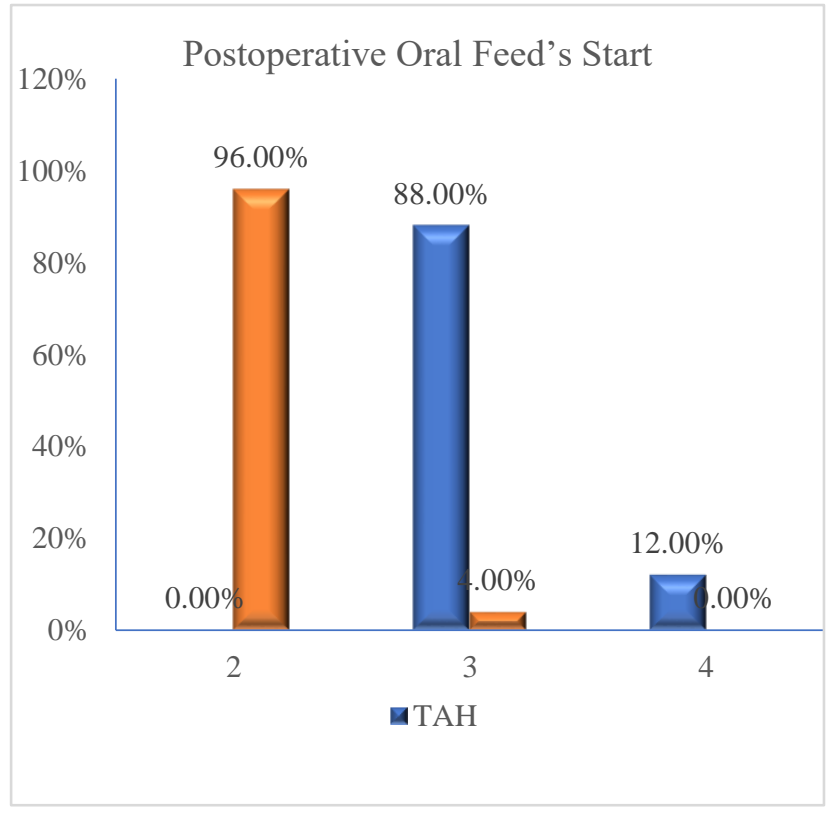

Figure 2: Distribution of groups according to postoperative oral feed's start day. 


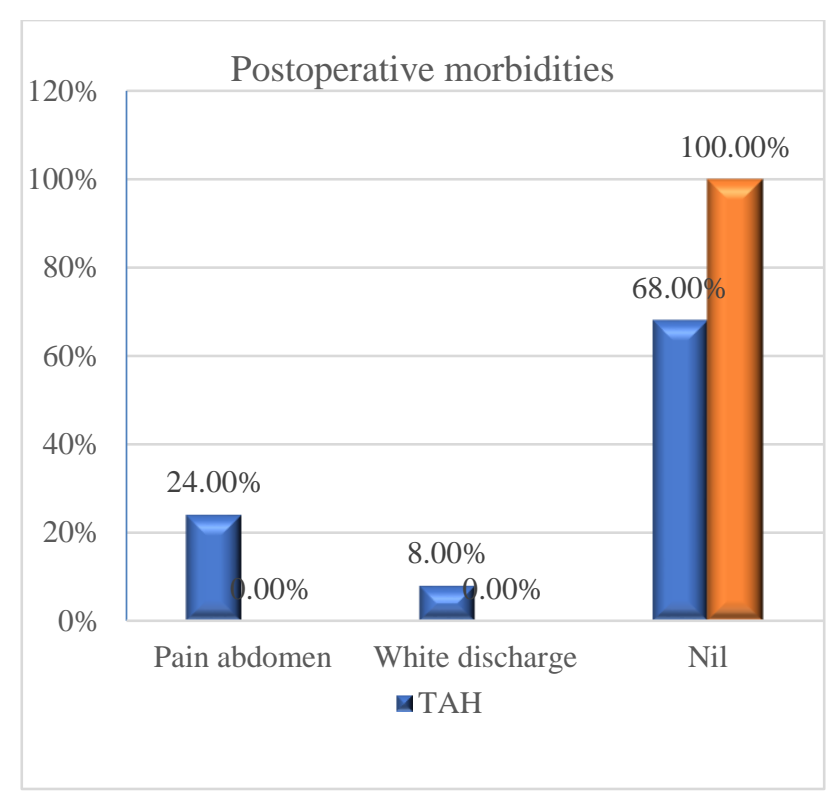

Figure 3: Follow up morbidity wise distribution between groups.

In almost all cases (96\%) oral feeding was started on 2nd POD in TLH cases as compared to $88 \%$ cases on 3 rd day in TAH cases.

Mean hospital stay after TLH was much shorter than TAH cases, which was statistically highly significant.

There was none postoperative morbidity after TLH as compared to TAH cases.

Oopherectomy was required in only $60 \%$ of cases after TLH as compared to $96 \%$ in TAH.

All patients were highly satisfied after TLH as compared to only $56 \%$ after TAH.

\section{DISCUSSION}

A hysterectomy is a safe procedure with a low mortality rate, estimated at 0.12 to 0.34 per 1000 surgeries. $^{20}$

In this study outcomes were compared among 50 patients (25 in each group). They were also followed 4 weeks after discharge for any postoperative complaints or complications. Among both surgery groups, mean age of patients for TLH was 44.68 years and for TAH 45.78 years. The current study showed that there was no statistically significant difference regarding age, parity, with history of previous pelvic surgery, intraoperative complications, postoperative blood transfusion.

The current study showed no intraoperative complication in TLH group compared to TAH group (4\%), which was statistically non-significant $(\mathrm{p}=0.31)$. Bladder injury happened during the TAH group in one patient while dissection of the UV fold of peritoneum as bladder was

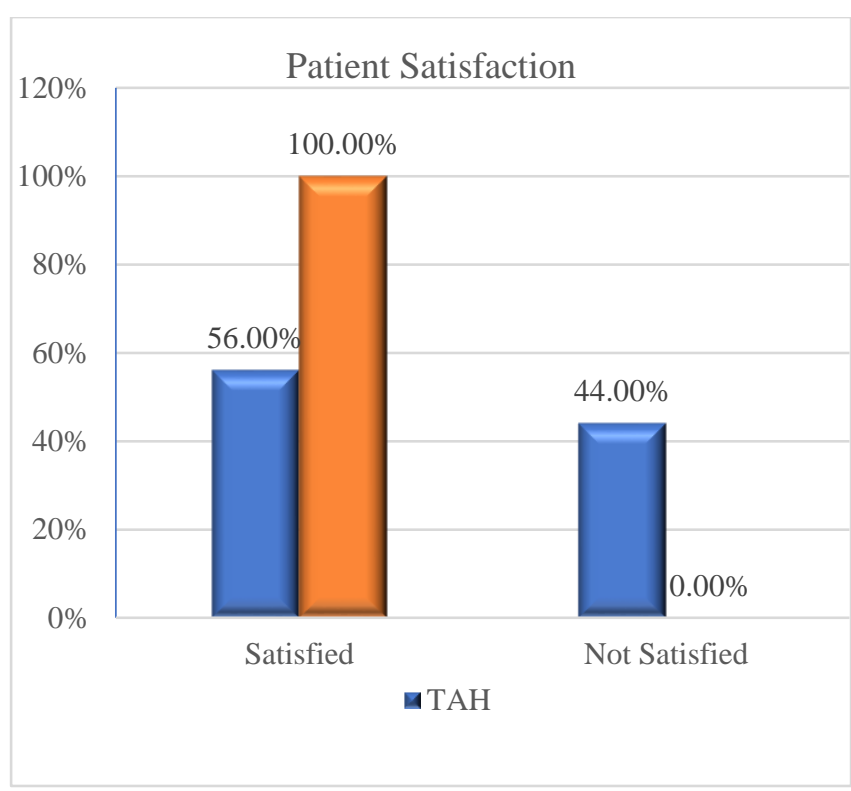

Figure 4: Patient satisfaction wise distribution between groups.

densely adherent to that site. Similar result was suggested by Mallick et al in 2016 who reported that the intraoperative complication rates were significantly less in the TLH group. ${ }^{21}$

In current study there was significant comparison found on the basis of postoperative complications like wound gaping in both surgical groups $(p=0.009)$. In TLH group no postoperative complication happened but in TAH group, $4 \%$ had fever and $24 \%$ of the patients had wound gaping. Similar result was suggested by other study. ${ }^{22}$

The current study showed that TLH group had early ambulation compared to TAH group. Mean mobility days difference was highly significant between TLH and TAH $(2.24 \pm 0.44$ versus $3.12 \pm 0.33, \mathrm{p}<0.001)$, most of patients (76\%) in the TLH group had ambulation in 2nd postoperative day and only some patients (24\%) had ambulation in 3rd postoperative day because they experience pain abdomen comparatively more and in the TAH group most of patients $(22 \%)$ had ambulation in $3 \mathrm{rd}$ postoperative day and some patients $(12 \%)$ in 4 th postoperative day. Similar results were reported by Gupta et al in their comparative study between TLH and conventional TAH in non-neoplastic uterine diseases. ${ }^{23}$

In present study the comparison regarding postoperative day of catheter removal was significant between TLH and TAH groups $(2.00 \pm 0.00$ versus $3.96 \pm 2.92 ; \mathrm{p}=0.002)$. In TLH group catheter was removed on second postoperative day in all patients, but in TAH group in $88 \%$ (22) of patient's catheter were removed on third day, but in $4 \%$ (1) patient on 5 th day and in $4 \%$ (1) patient in 7 th day because bladder adherent to lower uterine segment and in $4 \%$ (1) patient on $21 \mathrm{st}$ day because there was bladder injury happened. Prolonged catheterization was known to be associated with increased risk of urinary tract infection as 
well as delayed mobilization and prolonged hospital stay. ${ }^{24}$ Additionally, patients have reported that they find the indwelling catheter inconvenient. ${ }^{25}$

Current study showed statistically significant difference on the basis of start of oral feed (semi solid) in between TLH and TAH group $(2.08 \pm 0.28$ versus $3.12 \pm 0.33 ; \mathrm{p}<0.001)$. In the TLH group semisolid oral feed started on 2 nd postoperative day of all patients but in TAH group most of patients $(88 \%)$ semisolid food started on 3rd postoperative day because they experience more abdominal pain and in some patients (12\%) on 4th postoperative day because they experience gaseous abdominal distension. Other studies also suggested benefits of early oral feeds. ${ }^{26}$ Early oral feeding has been associated with a faster recovery of intestinal function. ${ }^{27}$

In current study, difference in the length of hospital stay was highly significant which was shorter with TLH than TAH (4.40 \pm 1.15 versus $10.32 \pm 8.19$ days, respectively; $\mathrm{p}<0.001)$ patients of TLH group discharged in 3 to 5 days but in TAH group most patients $(84 \%)$ discharged in 6-10 days due to wider incision given on abdominal wall, other patients discharged on 21-35 days due to they have intraoperative and postoperative complications like bladder injury, fever and wound gaping. This was supported by the literatures..$^{28,29}$

There was significant difference found regarding previous sterilization between TLH and TAH group $(p=0.007)$, TLH group had less patients who were previously sterilized. On follow up of patients after four week a highly statistically significant difference was found between TLH and TAH $(\mathrm{p}<0.001)$ there was no morbidity in TLH group in comparison to TAH in which patients were complaints like pain abdomen at stich line $(24 \%)$, white discharge $(8 \%)$.

We observed significant difference on the basis of oophorectomy, TLH group had comparatively less oophorectomy done $(60 \%)$, because this group belong to younger age group and in TAH group oophorectomy was done in majority of patients $(96 \%)$ probably because most of the woman included might be of older age group/rural set up.

In current study patient satisfaction was found highly significant between TLH and TAH (100\% versus 56\%, $\mathrm{p}<0.001)$ similar result was showed by Gupta et al. ${ }^{23}$

The reason for better postoperative comfort in TLH was that it required only a small skin incision, thereby resulting in reduced postoperative pain and minimal blood loss. Consequently, patients can quickly resume the activities of daily living and TLH could contribute to patients' quality of life as also observed by Komatsu et al. ${ }^{30}$

Postoperative follow up of patients 4 weeks after discharge showed better quality of life, lesser morbidity and higher satisfaction rate in TLH group.
The major drawback for TAH was the scar and the complications associated with the scar like pain, fever, risk of wound infection and gaping. This was due to the smaller field of vision and it being a technically advanced method of surgery requiring more experience on the part of surgeon as dealing with the anatomy of the pelvis during TLH which was difficult. Thereby increasing the procedure time and requiring more attention to complications such as intraoperative bladder and ureteral injury than TAH. Also, careful maintenance of hemostasis using an enlarged visual field and that of the transvaginal uterine manipulations were time consuming.

\section{CONCLUSION}

TLH is a safe and effective method of doing hysterectomy and it is a good alternative of conventional abdominal hysterectomy, especially after good training to standardized the procedure, proper case selection, day to day practice of the technique and application of sound surgical principles. TLH is definitely a better procedure owing to lesser tissue trauma, better cosmesis, reduced hospitalized duration, less postoperative pain \& analgesic requirement, and early ambulation as compared to TAH.

Funding: No funding sources

Conflict of interest: None declared

Ethical approval: The study was approved by the Institutional Ethics Committee

\section{REFERENCES}

1. Nogueira-Silva C, Santos-Ribeiro S, Barata S, Alho C, Osorio F, Calhaz-Jorge C. Total laparoscopic hysterectomy: retrospective analysis of 262 cases. Acta Med Port. 2014;27(1):73-81.

2. Jones HW, Rock JA. Te Linde's operative gynecology. Abdominal hysterectomy. 10th ed. Philadelphia: Wolters Kluwer Health/Lippincott Williams and Wilkins; 2008.

3. Morton M, Cheung VY, Rosenthal DM. Total laparoscopic versus vaginal hysterectomy: a retrospective comparison. J Obstet Gynaecol Can. 2008;30(11):1039-44.

4. Kluivers KB, Johnson NP, Chien P, Vierhout ME, Bongers M, Mol BW. Comparison of laparoscopic and abdominal hysterectomy in terms of quality of life: a systematic review. Eur J Obstet Gynecol Reprod Biol. 2008;136(1):3-8.

5. Walsh CA, Walsh SR, Tang TY, Slack M. Total abdominal hysterectomy versus total laparoscopic hysterectomy for benign disease: a meta-analysis. Eur J Obstet Gynecol Reprod Biol. 2009;144(1):3-7.

6. Nieboer TE, Johnson N, Barlow D. Surgical approach to hysterectomy for benign gynaecological disease. Coch Data Systemat Rev. 2009;3:3677.

7. Whiteman MK, Hillis SD, Jamieson DJ, Morrow B, Podgornik MN, Brett KM, et al. Inpatient hysterectomy surveillance in the United States, 20002004. Am J Obstet Gynecol. 2008;198(1):34-7. 
8. Franchi M, Ghezzi F, Buttarelli M, Tateo S, Balestreri D. Incisional hernia in gynecologic oncology patients: a 10-year study. Obstet Gynecol. 2001;97:696-700.

9. Obermair A, Manolitsas TP, Leung Y, Hammond IG, McCartney AJ. Total laparoscopic hysterectomy versus total abdominal hysterectomy for obese women with endometrial cancer. Int $\mathrm{J}$ Gynecol Cancer. 2005;15(2):319-24.

10. Reich H. New techniques in advanced laparoscopic surgery. Baillieres Clin Obstet Gynaecol. 1989;3(3):655-81.

11. Nezhat F, Nezhat C, Gordon S, Wilkins E. Laparoscopic versus abdominal hysterectomy. J Reprod Med. 1992;37(3):247-50.

12. Garry R, Fountain J, Brown J, Manca A, Mason S. Evaluate hysterectomy trial: a multicentre randomised trial comparing abdominal, vaginal and laparoscopic methods of hysterectomy. Health Technol Assess. 2004;8(26):1-154.

13. Graves EJ. National Hospital Discharge Survey: Annual Summary, 1992. Vital Health Stats 13. 1994;119:1-63.

14. Summitt RL, Stovall TG, Lipscomb GH, Ling FW. Randomized comparison of laparoscopy assisted vaginal hysterectomy with standard vaginal hysterectomy in an outpatient setting. Obstet Gynecol. 1992;80(6):895-901.

15. Boike GM, Elfstrand EP, DelPriore G, Schumock D, Holley HS, Lurain JR. Laparoscopically assisted vaginal hysterectomy in a university hospital: Report of 82 cases and comparison with abdominal and vaginal hysterectomy. Am J Obstet Gynecol. 1993;168:1690-701.

16. McPherson K, Herbert A, Judge A, Clarke A, Bridgman S, Maresh M, et al. Psychosexual health 5 years after hysterectomy: population-based comparison with endometrial ablation for dysfunctional uterine bleeding. Health Expectat. 2015;8(3):234-43.

17. Farquhar CM, Sadler L, Harvey SA, Stewart AW. The association of hysterectomy and menopause: a prospective cohort study. Int J Obstetr Gynaecol. 2005;112(7):956-62.

18. Massimo C, Stefano I, Alessandro B, Riparini J, Ronzoni S, Marconi A. Laparoscopic versus vaginal hysterectomy for benign pathology. Am J Obstet Gynecol. 2009;200(4):465-6.

19. Rock JA, Howard WJ. Laparoscopic hysterectomy. Te Linde's operative gynecology. 10th ed. Philadelphia: Wolters Kluwer/Lippincott Williams and Wilkins; 2008: 763-73.
20. Falcone T, Walters MD. Hysterectomy for benign disease. Obstet Gynecol. 2008;111(3):753-67.

21. Mallick R, English J, Waters N. Total laparoscopic hysterectomy versus total abdominal hysterectomy in the treatment of benign gynaecological disease: a retrospective review over 5 years. Gynecol Surg. 2016;13(4):359-64.

22. Harkki-Siren P, Sjoberg J, Toivonen J, Tiitinen A. Clinical outcome and tissue trauma after laparoscopic and abdominal hysterectomy: a randomized controlled study. Acta Obstet Gynecol Scand. 2000;79(10):866-71.

23. Gupta P, Chandra S, Kulshrestha R, Kulshrestha MR, Ghai S. A comparative study between total laparoscopic hysterectomy (TLH) and conventional total abdominal hysterectomy (TAH) in nonneoplastic uterine diseases. Int $\mathrm{J}$ Clin Obstet Gynaecol. 2020;4(3):188-91.

24. Liang CC, Lee CL, Chang TC, Chang YL, Wang CJ, Soong YK. Postoperative urinary outcomes in catheterized and non-catheterized patients undergoing laparoscopic-assisted vaginal hysterectomy - a randomized controlled trial. Int Urogynecol J Pelvic Floor Dysfunct. 2009;20(3):295-300.

25. Dunn TS, Shlay J, Forshner D. Are in-dwelling catheters necessary for 24 hours after hysterectomy? Am J Obstet Gynecol. 2003;189(2):435-7.

26. Charoenkwan K, Matovinovic E. Early versus delayed oral fluids and food for reducing complications after major abdominal gynaecologic surgery. Coch Data Systemat Rev. 2014;12:004508.

27. Bisgaard T, Kehlet H. Early oral feeding after elective abdominal surgery-what are the issues? Nutrition. 2002;18(11-12):944-8.

28. 28. Pather S, Loadsman JA, Mansfield C, Rao A, Arora V, Philp S et al. (2011): Perioperative outcomes after total laparoscopic hysterectomy compared with fast-track open hysterectomy - a retrospective case control study. ANZJOG., 51(5): 393-6.

29. American College of Obstetricians and Gynecologists. Choosing the route of hysterectomy for benign disease. Obstet Gynecol. 2017;129(6):1559.

30. Komatsu H, Taniguchi F, Nagata H, Nakaso T, Nagaya Y, Tsukihara S. Retrospective evaluation of the crucial factor in total laparoscopic hysterectomy by using video review. Laparosc Surg. 2019;3(23).

Cite this article as: Goyal SK, Chauhan M, Kanwat B, Mehra D. A comparative study between total laparoscopic hysterectomy and total abdominal hysterectomy for benign uterine pathologies at tertiary care institute, Udaipur. Int J Reprod Contracept Obstet Gynecol 2021;10:3806-11. 